\title{
Centrifuge study on damage mechanism of buried pipes in the liquefiable ground
}

\author{
Tetsuo Tobita ${ }^{\text {i) }}$, Keita Uratani ${ }^{\text {ii) }}$ and Takayuki Ashino ${ }^{\text {ii) }}$ \\ i) Associate Professor, Disaster Prevention Research Institute, Kyoto University, Gokasho, Uji, 611-0011, Japan. \\ ii) Graduate School of Engineering, Kyoto, Dept. of Civil and Earth Resources Engineering, Kyoto University, Nishikyo-ku, Kyoto, \\ 615-8530, Japan
}

\begin{abstract}
Large-scale liquefaction was caused by the 2011 off the Pacific coast of Tohoku, Japan, earthquake and many pipes in the liquefied ground suffered serious damages. One of the issues pointed out after the earthquake is the dynamic behavior and the mechanism of pipes near a structure in the liquefied ground. This study focuses on evaluating the dynamic behavior through centrifuge model test. Test results show that the uplift of pipes in the liquefied ground occurred during an earthquake and liquefaction happens at that time. After an earthquake, pipes start to sink with increasing effective stress. The characteristic of damage mechanism depends on the depth of pipes and the state of ground (in liquefiable layer, at ground water level, or in the unsaturated layer). The data also shows that the direction of force interacting pipes during liquefaction was only bending direction. So we should reconsider the design criteria for pipes which is widely used in Japan applying to axial force.
\end{abstract}

Keywords: centrifuge modeling, pipes, liquefaction, dynamic

\section{INTRODUCTION}

The 2011 off the Pacific coast of Tohoku, Japan, earthquake caused tremendous damage to north-eastern part of Japan, from Kanto to Tohoku regions. Many pipelines in the liquefied ground suffered serious damages (Yamaguchi et al., 2012). One of the issues pointed out after the earthquake is the dynamic behaviour of pipes near a structure in the liquefied ground is still unknown. In the past many research efforts have been made to study dynamic behaviour of pipes in the liquefied ground [e.g., Ling et al. (2003), Uzuoka and Tateishi (2003), Cheuk et al. (2008), Kiku (2004), Tateishi et al. (2009), Tobita et al. (2009), Uno et al. (2009), Chou et al. (2010), Koseki et al.(1997)]. Hachiya et al. (2005) developed a design method of pipelines considering forces applied along the longitudinal direction. In this study, the centrifuge model test was conducted to evaluate the dynamic behaviour of a buried pipes and investigate its failure mechanism.

\section{EXPERIMENTAL METHODOLOGY}

The centrifuge model test was carried out under a $40 \mathrm{~g}$ centrifugal field. A schematic view of experimental setup is shown in Fig. 1. Concrete mixed sands were used for non-liquefiable layer at the bottom. Above the non-liquefiable layer, liquefiable layer was made of loose silica sand $(\mathrm{Dr}=40 \%)$ by air pluviation. After that, the model ground was filled with a viscous fluid (Fig.
3). Above the loose sand layer, unsaturated layer was also made of the same silica sand by air pluviation.

Square steel pipes were fixed to the bottom of the container, on which model pipes were rigidly connected through the flange plate (Table 1 and Fig. 2). The model pipes used in this experiment were made from stainless steel. It is $18.48 \mathrm{~m}$ long and has outer diameters of $1.36 \mathrm{~m}$ in prototype scale. Four model pipes were placed at the designated depth (Fig. 1). Strain gages were attached inside wall of the pipes (Fig. 2). A sinusoidal input acceleration was given with a prototype maximum acceleration of $200 \mathrm{gal}$ and frequency of $1 \mathrm{~Hz}$ for the duration of 60 seconds.

As shown in Fig. 1, in total 4 model pipes were implemented and shaken simultaneously. Model A was buried in the liquefiable layer (GL. $-5.0 \mathrm{~m}$ ) and Model $\mathrm{C}$ was in the unsaturated layer (GL. $-1.5 \mathrm{~m}$ ). Both Model B and Model D were installed at the groundwater level (GL.-3.0 m). Model D was provided with an angular roof as a liquefaction measure (Fig. 4) for the purposes of distributing load and reducing settlement of the pipe during liquefaction.

Accelerometers both measuring horizontal and vertical motions, and pore water pressure transducers are installed in the location shown in Fig. 5. Targets of the laser displacement transducers are attached to the tips of 4 pipes, liquefiable layer, groundwater level, and ground surface through the settlement gages. 
Table 1 Material and dimensions of model pipe

\begin{tabular}{c|c}
\hline & Model (Prototype) scale \\
\hline Material & SUS304 \\
\hline Length & $462 \mathrm{~mm}(18.4 \mathrm{~m})$ \\
\hline O.D. & $34 \mathrm{~mm}(1.36 \mathrm{~m})$ \\
\hline Thickness & $1.65 \mathrm{~mm}(6.6 \mathrm{~cm})$ \\
\hline Young's modulus & $1.93 \times 10^{8} \mathrm{kN} / \mathrm{m}^{2}$ \\
\hline Section modulus, I & $2.20 \times 10^{4} \mathrm{~mm}^{4}\left(5.63 \times 10^{-2} \mathrm{~m}^{4}\right)$ \\
\hline Bending stiffness, El & $4.24 \times 10^{6} \mathrm{kNmm}\left(1.09 \times 10^{7} \mathrm{kNm}^{2}\right)$ \\
\hline Density & $1,500 \mathrm{~kg} / \mathrm{m}^{3}$ \\
\hline
\end{tabular}
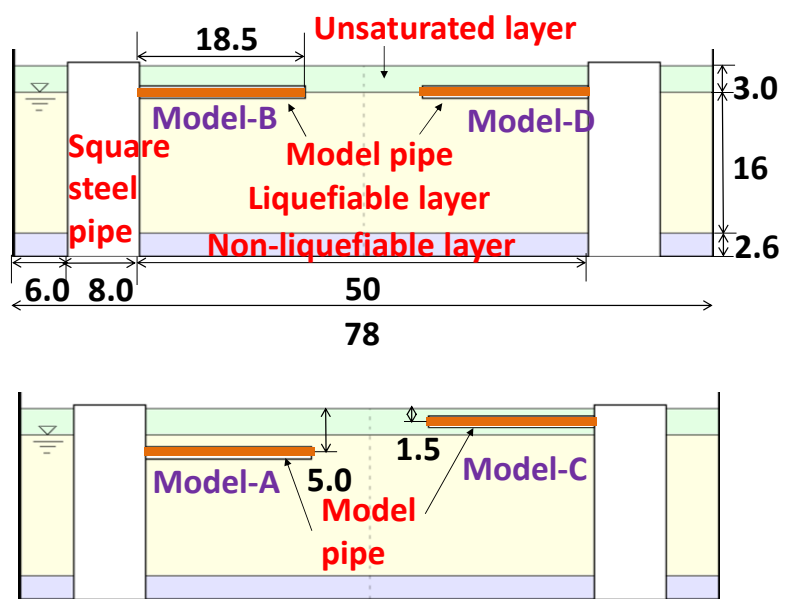

Units in (m) (prototype scale)

Fig.1 Schematic view of experimental setup

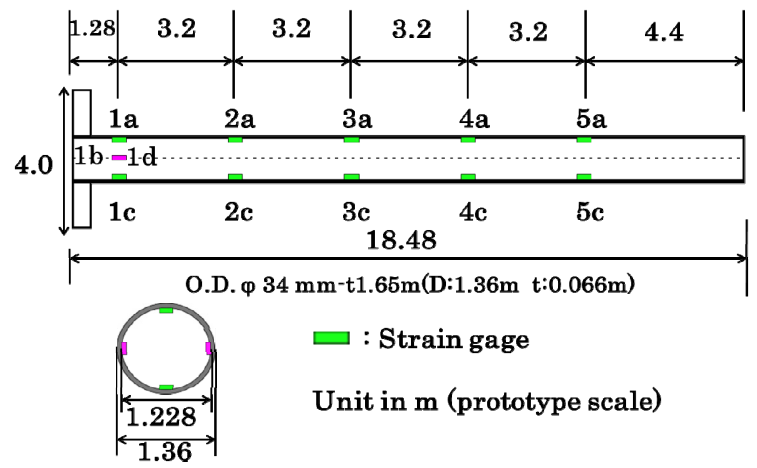

Fig.2 Illustration of the model pipe

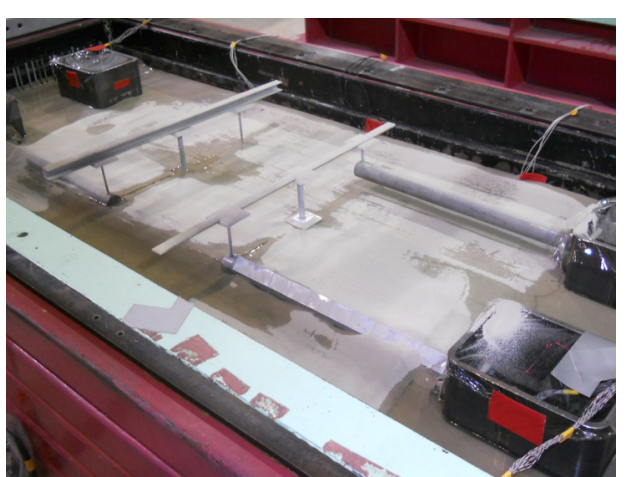

Fig. 3 A view of the model ground after saturation.

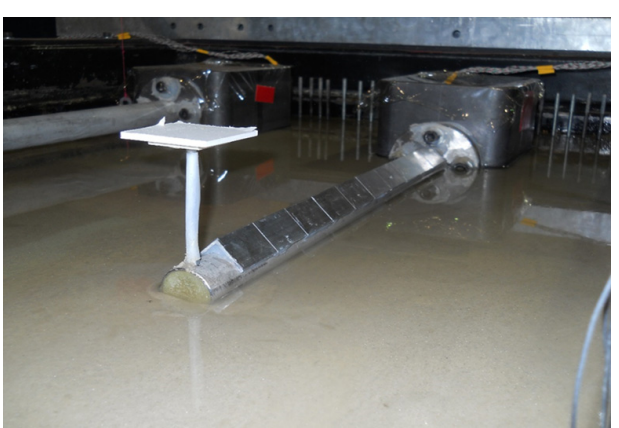

Fig. 4 Model D with angular roof

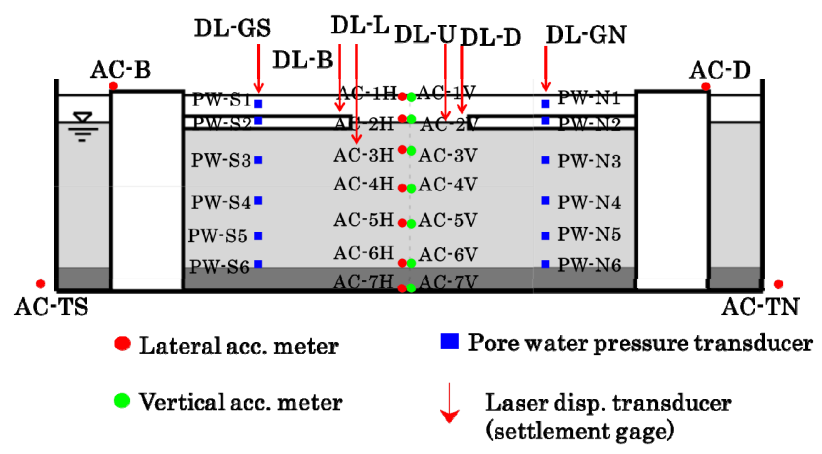

Fig. 5 Locations of sonsors

\section{RESULTS AND DISCUSSION}

Relationship between the input acceleration and excess pore water pressure ratio (Fig. 6) shows that the horizontal shaking was given approximately from 20 $\mathrm{sec}$ to $80 \mathrm{sec}$, and just after the shaking starts, excess pore water pressure ratio increased rapidly and at 10 seconds, excess pore water pressure ratio reached near to 1.0 , i.e., liquefaction happened. After that, excess pore water pressure ratio gradually decreased to zero for about 1,000 seconds.

Vertical displacement of tips of the pipes and ground show [Fig. 6(b)] that ground (including surface, liquefiable layer, and groundwater level) continuously settles, while all pipe tips uplifted during shaking and then start to settle as the shaking stops [Fig. 6(a)]. Except for Model C (pipe in the unsaturated layer), it remained uplifted. Pipes seem to start to sink with the settlement of surrounding soil due to liquefaction. An instantaneous settlement of tips of pipe about $20 \mathrm{~mm}$ is observed at the beginning of shaking. Then, after liquefaction occurred at 30 seconds, pipes started to uplift due to movement of liquefied sands. After the duration of shaking, pipes start to move downward with the settlement of surrounding soil. 


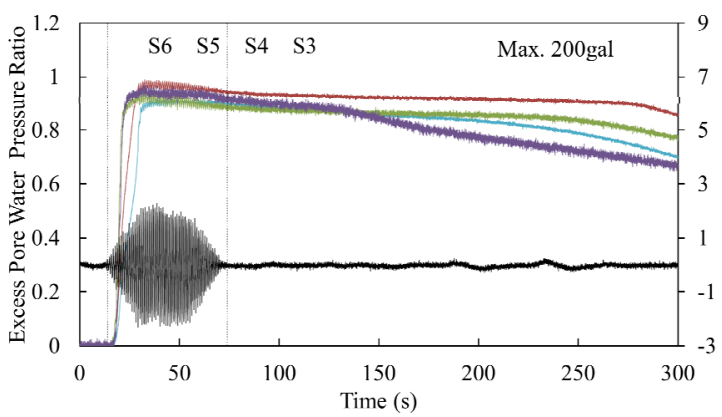

Fig. 6 relationship between lateral acceleration and excess water pressure ratio
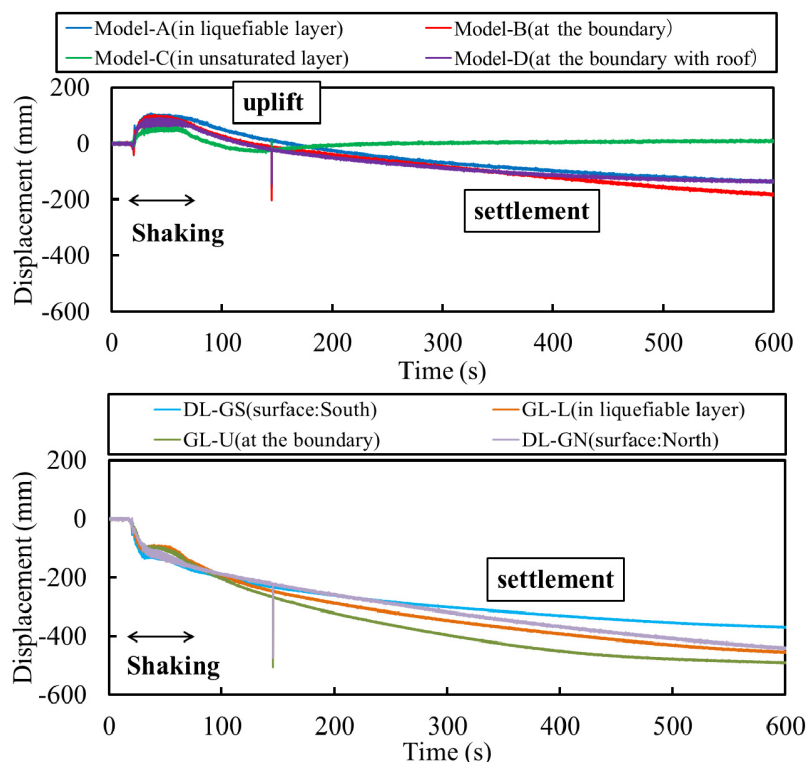

Fig. 7 Vertical displacement of (a) pipes (b) ground

To see the efficiency of a measures for liquefaction, Fig. 8 compares the amount of vertical displacements at specified instances for Model B (without angular roof) and Model D (with angular roof). Both model pipes were buried at the boundary between liquefied and non-liquefied layer (GL. $-3.5 \mathrm{~m}$ ). Figure 8 shows that the initial settlement occurred in the process of achieving centrifugal acceleration of $40 \mathrm{~g}$, then pipes are uplifted during shaking, and finally they settle. The initial settlement of Model D was about $2 \mathrm{~mm}$ larger than that of Model B because of the weight of angular roof. However, uplift displacement of Model D was 10\% less than that of Model B. Moreover, the final settlement of Model D was $20 \%$ less than Model B. Based on this observation, the measures with angular roof may reduce the amount of both uplift and settlement. True mechanism responsible for this phenomenon is unknown, however, soils near the apex of angular roof might be failed due to concentration of stresses, and they moved along with the slope of angular roof. So the force interacting on the pipe was reduced. Further discussion about this mechanism is required in the future.

Figure 9 is the time histories of the strain of upper-and-lower surface of the root of pipe near a structure. Strains of opposite side show positive and negative values in all models. Hence, the direction of the force interacting on the pipe during liquefaction was only bending direction, not in the longitudinal direction. Based on these data, the maximum bending moments of pipes from the strain is calculated, and the results show that the maximum bending moments are observed near a structure. This indicates why the most of pipe damage were occurred at the area near a structure. The design guideline of water pipes widely used in Japan specifies the axial force induced by skin frictional force, not bending moment, to prevent from dislocating pipe connections. According to the current design criteria, the maximum force applied at the pipe joints should be 3D kN [D: outer diameter (mm)]. This formula is set up from friction force per unit area during an earthquake in consideration of a safety factor. This formula excludes the process of liquefaction, and a new design criteria based on the maximum bending moment induced on a pile, especially, near a structure may be needed for pipes in a liquefiable ground.

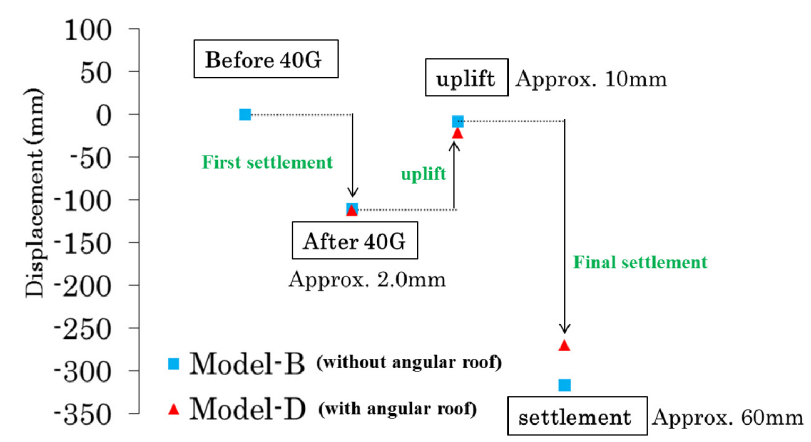

Fig.8 Comparison of vertical displacement between Model B and Model D
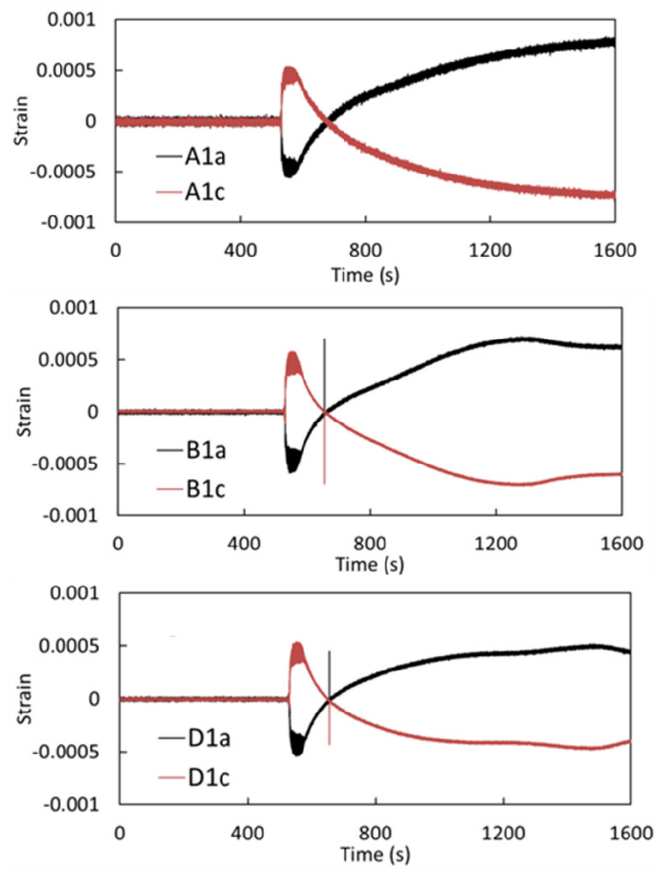

Fig.9 maximum strain of upper-and-lower surface of pipes

\section{CONCLUSIONS}

Dynamic behavior of pipes under liquefied condition near a structure was studied through centrifuge model test. As soon as earthquake occurred, pipes sink about $20 \mathrm{~mm}$ 
once and then uplifted about $100 \mathrm{~mm}$. At that time, excess pore water pressure ratio reaches 1.0, i.e., liquefaction happens. After stopping shaking, pipes started to sink about $300 \mathrm{~mm}$ with increasing effective stress in the liquefied layer. Settlement of the pipe buried at the groundwater level (boundary between liquefiable and non-liquefiable layer) was the largest. However, the pipe buried in the unsaturated layer remained uplifted. By using angular roof as a liquefaction measure, we could successfully reduce the uplift of pipes by $10 \%$ and settlement of pipes by $20 \%$. True mechanism responsible for this phenomenon is unknown, however, soils near the apex of angular roof might be failed due to concentration of stresses, and they moved along with the slope of angular roof. So the force interacting on the pipe was reduced. Further discussion about this mechanism is required.

The strains of upper-and-lower inner surface of pipe were positive and negative value in all models. Hence, only bending moments were activated on the pipe during liquefaction. The computed maximum bending moments of pipes from the strain showed that most of bending moments were appeared at the area near a structure. It indicates that most of pipe damage may occur near a structure at the fixed ends. However, the design guideline of water pipes widely used in Japan only specifies axial force induced by skin frictional force, and the value for bending moments are not given. A new design criteria for the maximum bending moment induced on a pile near a structure may be needed especially for pipes in the liquefiable ground.

\section{ACKNOWLEDGEMENTS}

This study was partially supported by the grants awarded from the Kansai Research Foundation for technology promotion (2013R151) and the Ministry of Education, Science, Sports and Culture, Grant-in-Aid for Scientific Research (A), No. 26249067 (PI: Prof. Junji Kiyono, Kyoto Univ.). Constructive comments and suggestions made by the members of research committee for intelligent seismic remediation measures of water network systems in the Japanese Society of Civil Engineers, Dr. Yasuko Kuwata (Kobe Univ.), Dr. Kiyoshi Sato (Obayashi Co.), Dr. Yasuhiko Konishi (Nissuikon Co.), Mr. Katsutoshi Miyamoto (Nissuikon Co.), and Yoshio Sunasaka (Kajima Co.) are greatly acknowledged.

\section{REFERENCES}

1) Cheuk, C. K., White, D. J. and Bolton, M. D. (2008): Uplift mechanism of pipes buried in sand, Journal of Geotechnical and Geoenvironmental Engineering, 134(2), 154-163.

2) Chou, J. C., Kutter, B., L., Travasarou, T. and Chacko, J. M. (2010): Centrifuge modeling of seismically-induced uplift for the BART transbay tube, Journal of Geotechnical and Geoenvironmental Engineering. 137(8), 754-765.

3) Kiku, H., Yasuda, S., Tanaka, T. and Itou, T. (2004): Damage of sewerage systems in Toyokoro town during the 2003 Tokachi-oki, Japan, Earthquake, The 59nd Japan National Conference on Civil Engineering, 423-424 (in Japanese).

4) Koseki, J., Matsuo, O. and Koga, Y. (1997): Uplift behavior of underground structures caused by liquefaction of surrounding soil during earthquake, Soils and Foundations, 37(1), 97-108.

5) Ling, H., I., Mohri, Y., Kawabata, T., Liu, H., Burke, C. and Sun, L. (2003): Centrifuge modeling of seismic behavior of large-diameter pipe in liquefiable soil, Journal of Geotechnical and Geoenvironmental Engineering, 129(12): 1092-1101.

6) Tateishi, A., Oka, F., Kotani, Y. and Asai, R. (2009): Numerical analysis of uplift behavior of an underground structure due to liquefaction using an effective stress analysis method, Performance-Based Design in Earthquake Geotechnical Engineering, T. Kokusho, Y. Tsukamoto and M. Yoshimine (eds) Taylor and Francis Group, London, ISBN978-0-415-55614-9, 1071-1079.

7) Tobita, T., Iai, S., Kang, G.-C. and Konishi, Y. (2009): Observed damage of wastewater pipelines and estimated manhole uplifts during the 2004 Niigataken Chuetsu, Japan, earthquake, Lifeline Earthquake Engineering in a Multihazard Environment, TCLEE2009, Oakland, California, USA, 791-802.

8) Uno, H., Oka, F., Tanizaki, S. and Tateishi, A. (2009): Centrifuge model tests on the uplift behavior of an underground structure during liquefaction and its numerical modeling, Performance-Based Design in Earthquake Geotechnical Engineering, T. Kokusho, Y. Tsukamoto and M. Yoshimine (eds) Taylor and Francis Group, London, ISBN987-0-415-55614-9, 1041-1049.

9) Uzuoka, R. and Tateishi, A. (2003): 2-dimensional effective stress analysis on uplift of buried pipe in liqufied ground, The 48th Geotechnical Engineering Symposium (Jiban kogaku Symposium), Japanese Geotechnical Society, 239-246 (in Japanese).

10) Yamaguchi, A., Mori, T., Kazama, M. and Yoshida, N. (2012): Liquefaction in Tohoku district during the 2011 off the Pacific Coast of Tohoku Earthquake, Soils and Foundations, 52(5), 811-829. 